\title{
Localized Sources of Neurotrophins Initiate Axon Collateral Sprouting
}

\author{
Gianluca Gallo and Paul C. Letourneau \\ University of Minnesota, Department of Cell Biology and Neuroanatomy, Minneapolis, Minnesota 55455
}

The sprouting of axon collateral branches is important in the establishment and refinement of neuronal connections during both development and regeneration. Collateral branches are initiated by the appearance of localized filopodial activity along quiescent axonal shafts. We report here that sensory neuron axonal shafts rapidly sprout filopodia at sites of contact with nerve growth factor-coated polystyrene beads. Some sprouts can extend up to at least $60 \mu \mathrm{m}$ through multiple bead contacts. Axonal filopodial sprouts often contained microtubules and exhibited a debundling of axonal microtubules at the site of bead-axon contact. Cytochalasin treatment abolished the filopodial sprouting, but not the accumulation of actin filaments at sites of bead-axon contact. The axonal sprouting response is mediated by the trkA receptor and likely acts through a phosphoinositide-3 kinase-dependent pathway, in a manner independent of intracellular $\mathrm{Ca}^{2+}$ fluctuations. These findings implicate neurotrophins as local cues that directly stimulate the formation of collateral axon branches.

Key words: sprouting; NGF; neurotrophin; collateral branch; actin; cytoskeleton
The establishment of neuronal connections depends on the ability of the cortex and cytoplasm of elongating axons to undergo dynamic reorganization in response to extrinsic guidance cues. Similarly, neuronal connectivity patterns are refined via alterations in both cell morphology and physiology. The sprouting of new motile structures (e.g., filopodia and lamellae) from previously quiescent regions of a neuron is fundamental to these dynamic morphological changes. It is therefore of great importance to understand the signals that regulate neuronal morphology and the mechanisms through which they act.

Dynamic reorganization of the cytoskeleton underlies cellular motile behaviors (Theriot and Mitchison, 1991; Bentley and O’Connor, 1994; Lin et al., 1994; Tanaka and Sabry, 1995; Challacombe et al., 1996). Actin filaments are involved in the generation and maintenance of the filopodia and lamellipodia that are crucial to the growth and guidance of nerve fibers (Bentley and Toroian-Raymond, 1986; Chien et al., 1993; Gomez and Letourneau, 1994). The development of neuronal connections is attributable mainly to the activities of growth cones located at the distal tips of elongating nerve fibers. However, some neuronal connections are formed by axonal branches that arise de novo behind the distal growth cone (O'Leary and Terashima, 1988; Heffner et al., 1990; Bhide and Frost, 1991; O'Leary et al., 1991; Ghosh and Shatz, 1992; Kadhim et al., 1993; O'Leary and Koester, 1993; Kennedy and Tessier-Lavigne, 1995). Such novel branches (collateral branches) are initiated by the appearance

\footnotetext{
Received Feb. 23, 1998; revised April 30, 1998; accepted May 6, 1998.

This research was supported by National Institutes of Health Grant HD 19950-12 (P.C.L.) and a grant from the Minnesota Medical Foundation (P.C.L.). We thank Mr. P. Atkinson (University of Minnesota) for preparing the BDNF-coated beads and for critical comments on this manuscript; Regeneron (Dr. L. Palladino) for supplying BDNF; Dr. F. B. Lefcort (University of Montana at Bozeman) for providing the trkA antibody; Dr. L. Reichardt (University of California at San Francisco) for providing the Chex antibody; and Mr. J. Sedgewick and the staff of the Biomedical Imaging and Processing Laboratory (University of Minnesota) for assistance with the three-dimensional rendering.

Correspondence should be addressed to Dr. Gianluca Gallo, University of Minnesota, Department of Cell Biology and Neuroanatomy, 4-144 Jackson Hall, 321 Church Street SE, Minneapolis, MN 55455.

Copyright (C) 1998 Society for Neuroscience $\quad 0270-6474 / 98 / 185403-12 \$ 05.00 / 0$
}

along quiescent axon shafts of motile filopodia (Bastmeyer and O'Leary, 1996), which subsequently give rise to a new axonal branch. Collateral branches form at characteristic locations (O’Leary and Stanfield, 1985; Kuang and Kalil, 1994), perhaps in response to localized extrinsic cues.

Global applications of neurotrophins promote axon collateral branch formation in vivo (Schnell et al., 1994; Zhang et al., 1994; Cohen-Corey and Fraser, 1995; Sawai et al., 1996; Inoue and Sanes, 1997) and modulate growth cone filopodial morphology in vitro (Gundersen and Barrett, 1980; Connolly et al., 1985). Endogenous brain-derived neurotrophic factor (BDNF) mediates the formation of optic axon arborizations in the tectum (CohenCory and Fraser, 1995). During deinnervation-induced sprouting of sensory axons, endogenous nerve growth factor (NGF) induces the formation of collateral sprouts from fibers that had not been injured previously (Diamond et al., 1992; Gloster and Diamond, 1992). Endogenous NGF has also been shown to be involved in the collateral sprouting of cholinergic septohippocampal fibers (He et al., 1992; Van der Zee et al., 1992). Further support for NGF as a developmentally relevant regulator of axonal sprouting is provided by a study showing that target-produced NGF is necessary for the development of proper sympathetic branching density in target tissues (Hoyle et al., 1993).

Dorsal root ganglion (DRG) neurons undergo collateral sprouting during both development (Kudo and Yamada, 1987; Mendelson et al., 1992; Zhang et al., 1994; Ozaki and Snider, 1997) and regeneration (Devor et al., 1979; Doucette and Diamond, 1987) and are therefore a valid model for studying the role of extracellular cues in collateral branch formation. Importantly, endogenous NGF promotes the formation of collateral branches by DRG cells during regeneration (Diamond et al., 1987, 1992; Owen et al., 1989; Doubleday and Robinson, 1992), and exogenous NGF promotes DRG collateral sprouting during development (Zhang et al., 1994), suggesting that it is a developmentally relevant cue for collateral sprouting.

Previous studies have not determined whether neurotrophins act directly and locally on axons to promote collateral branch 
formation. In the present report we demonstrate that a localized source of neurotrophin can directly activate actin-dependent motility along axons via a phosphoinositide-3 (PI-3) kinasedependent pathway, resulting in the initial steps of collateral branch formation, filopodial extension, and a concomitant reorganization of the microtubule array of the axonal shaft.

\section{MATERIALS AND METHODS}

Cell culture. Cultures were prepared as described in Gallo et al. (1997). Embryonic day 9-10 chick embryo DRGs were enzymatically and mechanically dissociated, and cells were cultured overnight on fibronectin (Life Technologies, Grand Island, NY)-coated glass coverslips $(22 \times 22$ $\mathrm{mm}$ ). Cells were raised in F-12H medium (Life Technologies) containing $0.05 \mathrm{ng} / \mathrm{ml}$ NGF (R \& D Systems, Minneapolis, MN) or BDNF (Regeneron, Tarrytown, NY). This concentration of neurotrophin supports cell survival but is well below the dissociation constant for the high-affinity neurotrophin receptors, thereby not interfering with bead-bound neurotrophin signaling. The introduction of beads to cultures was accomplished by removing $100 \mu$ l of the culture medium and suspending $363 \times$ $10^{3}$ beads in it, and subsequently returning the bead-containing medium dropwise to the culture, assuring that the beads spread evenly on the surface of the coverslip. In some experiments (video microscopy and the determination of long collateral formation), $1452 \times 10^{3}$ beads were introduced into the culture.

Neurotrophin-coated beads. Neurotrophin-coated beads were prepared as described in Gallo et al. (1997) (also see Kuhn et al., 1995). Proteins were attached to carboxylated polystyrene beads using the carbodiimide method (all reagents and beads were obtained from Polysciences Inc., Warrington PA). Beads were washed twice with carbonate buffer and twice with phosphate buffer. After the washes, beads were activated by incubation in a $2 \%$ solution of carbodiimide for $4 \mathrm{hr}$ and subsequently washed three times using borate buffer. Beads were then washed with carbonate buffer and incubated in $50 \mu \mathrm{g} / \mathrm{ml} \mathrm{NGF}$ or BDNF overnight. The next day, beads were treated with $0.0125 \mathrm{M}$ ethanolamine in borate buffer for $30 \mathrm{~min}$. Beads were then washed twice in borate buffer containing $10 \mathrm{mg} / \mathrm{ml}$ bovine serum albumin (BSA) (Sigma, St. Louis, $\mathrm{MO})$ and stored in storage buffer at $4^{\circ} \mathrm{C}$. The entire protocol was performed at room temperature.

Immunocytochemistry. Cultures were fixed with $0.12-0.2 \%$ glutaraldehyde for $15 \mathrm{~min}$, treated with $1 \mathrm{mg} / \mathrm{ml}$ sodium borohydride for $15 \mathrm{~min}$, and then extracted with $0.1 \%$ Triton X-100 for $15 \mathrm{~min}$. Actin filaments were stained with $8 \mu \mathrm{l} / \mathrm{ml}$ phalloidin conjugated to either rhodamine or fluorescein (Molecular Probes, Eugene, OR) for $45 \mathrm{~min}$. Microtubules were stained using a monoclonal antibody raised against $\beta$-tubulin (Amersham, Arlington Heights, IL) and a secondary goat anti-mouse fluorescein-conjugated antibody (Cappel, Durham, NC). Cells were exposed to primary and secondary antibodies for $45 \mathrm{~min}$ each. Coverslips were then mounted in media containing $10 \mathrm{mg} / \mathrm{ml} \mathrm{p}$-phenylenediamine (Sigma) and stored at $-20^{\circ}$.

Data collection and experimental procedures. Axonal shaft responses ( $>60 \mu \mathrm{m}$ from the growth cone) to NGF-coated beads were categorized according to the number of filopodia present at the site of bead-axon contact. The absence of filopodia was scored as a no response. Responses were characterized by the presence of one or more filopodia at the site of bead-axon contact. Responses to BDNF-coated beads were also scored according to the presence or absence of filopodia. However, a more common morphological response of BDNF-raised neurons to BDNFcoated beads was the generation of lamellae-like structures, which were also counted as a positive response. Mounted coverslips were scanned using epifluorescence optics $(630 \times)$ while we focused at the level of the bead's largest diameter. When a bead was judged to be in contact with a nerve fiber, the plane of focus was lowered to that of the nerve fiber, and the behavior of the axonal shaft was scored. For each experimental data set, data were collected from a minimum of 50 separate nerve fibers from at least two cultures prepared with cells obtained from a minimum of three embryos. Bead-axon interactions were scored blind to the experimental treatment.

Experiments investigating the role of $\mathrm{Ca}^{2+}$ in the filopodial response were performed by changing the culture medium to a saline solution $2 \mathrm{hr}$ before the introduction of beads. The saline solution consisted of (in $\mathrm{mM}$ ): $10 \mathrm{HEPES}, 140 \mathrm{NaCl}, 5.6 \mathrm{KCl}, 1 \mathrm{MgCl}_{2}, 5.5$ glucose, 1 EGTA, and 0 or $2 \mathrm{CaCl}$ (all from Sigma), and contained $0.05 \mathrm{of} \mathrm{ng} / \mathrm{ml} \mathrm{NGF.}$

All drugs were prepared as stock solutions in DMSO and stored at $-20^{\circ} \mathrm{C}$. Final dilutions were prepared on the day of use. For all drugs, 100 $\mu \mathrm{l}$ of medium was removed from each culture and placed in a $1.5 \mathrm{ml}$ tube, and the drugs were then added to the isolated medium. Of the medium containing the $\operatorname{drug}(\mathrm{s}), 100 \mu \mathrm{l}$ was then returned to the culture, thereby providing rapid and even dispersal of the drug in the culture.

Video microscopic recordings of axonal motility at sites of NGF bead contact and of spontaneous axonal motility were performed as detailed in Gallo et al. (1997) using an interframe interval of $30 \mathrm{sec}$. Data of axon-bead contact were collected from 90 min recordings of 12 fields, containing 24 axons contacted by a total of 77 beads at high bead density (see "Cell culture" above). For determination of spontaneous axonal filopodial motility, data were collected from five cultures and 12 different axons. The life span of bead-associated filopodia was compared with that of the spontaneously generated axonal filopodia of $>5 \mu \mathrm{m}$ (half of a bead diameter), so as not to skew the analysis with data from short filopodia that could not have been detected in the bead experiments because of occlusion by the bead. All data in the text are presented as mean \pm SEM. Video observations were performed using a phase-contrast $40 \times$ objective with $6.3 \times$ intermediate magnification.

To study the induction of long axon collaterals by NGF beads, we obtained data from cultures stained for actin and microtubules as described previously. Collateral branches were defined as actin- and microtubule-containing projections from the main shaft of an axon having a minimum length of $20 \mu \mathrm{m}$. Only projections that had angles relative to the main axon greater than $45^{\circ}$ were considered collaterals, because previous observations (Yu et al., 1994) (G. Gallo, unpublished observations) indicated that branches formed by growth cone bifurcation tend to form at angles of $45^{\circ}$ or less. The following information was obtained for each collateral: (1) whether it had a bead positioned at its site of formation from the main axon shaft, (2) its length (from the axon shaft to its tip), and (3) the number of beads that it contacted along its length. To determine whether the association of multiple beads to a collateral branch was attributable to bead-induced extension of axonal sprouts versus the stochastic deposition of beads on previously existing collaterals, we compared the number of beads per unit length of neurite for collateral branches versus the main axonal shaft. If beads merely settled on axons and their collateral branches, the mean bead density should be equal on both neurite types. To provide more axon-bead contacts, we increased the density of beads added to cultures by fourfold (see "Cell culture").

We investigated the attachment of beads to neuronal somata to rule out the possibility that results obtained using cytochrome $c$ (CC) beads and NGF beads were caused by differential attachment of the beads to neuronal surfaces. Briefly, $3 \mu \mathrm{m}$ beads were coated with either CC or NGF as described previously. Beads were incubated with established DRG neuronal cultures for $30 \mathrm{~min}$. The medium from the culture was then removed and pipetted onto the culture five times at a rate of $\sim 1$ $\mathrm{ml} / 5 \mathrm{sec}$. This displaced neuronal somata and left behind attached non-neuronal cells. The medium containing neuronal somata was then placed on a videomicroscopy dish, and cells were allowed to settle for 30 min. The numbers of beads associated with individual neuronal somata were counted using phase-contrast optics.

\section{RESULTS}

\section{Characterization of axonal sprouting responses to NGF bead contact}

Axons sprout filopodia in response to NGF-coated beads

To locally apply neurotrophins, NGF was covalently conjugated to polystyrene beads as reported previously (Gallo et al., 1997) (see Materials and Methods), and NGF-coated beads were added to established dorsal root ganglion neuronal cultures. The cultures were then fixed at $0.5,1$, and $3 \mathrm{hr}$ after the addition of the beads. Cultures were subsequently stained with phalloidin to visualize structures rich in actin filaments. Although not visible with phase-contrast optics, axons sprouted filopodia at sites of bead contact as revealed by actin filament phalloidin fluorescence (Fig. 1). The number of filopodia generated at the contact site varied, as did the overall morphology of the sprouts. By $3 \mathrm{hr}$ of contact, $33 \%$ of sprouts $(n=266)$ had developed a swollen appearance and contained F-actin puncta (Fig. $1 A, C$ ). Filopodia were extended at sites of bead contact with axons by as early as 30 min after bead addition, and the percentage of axonal responses to bead contacts increased with time over a $3 \mathrm{hr}$ period (Table 1). 

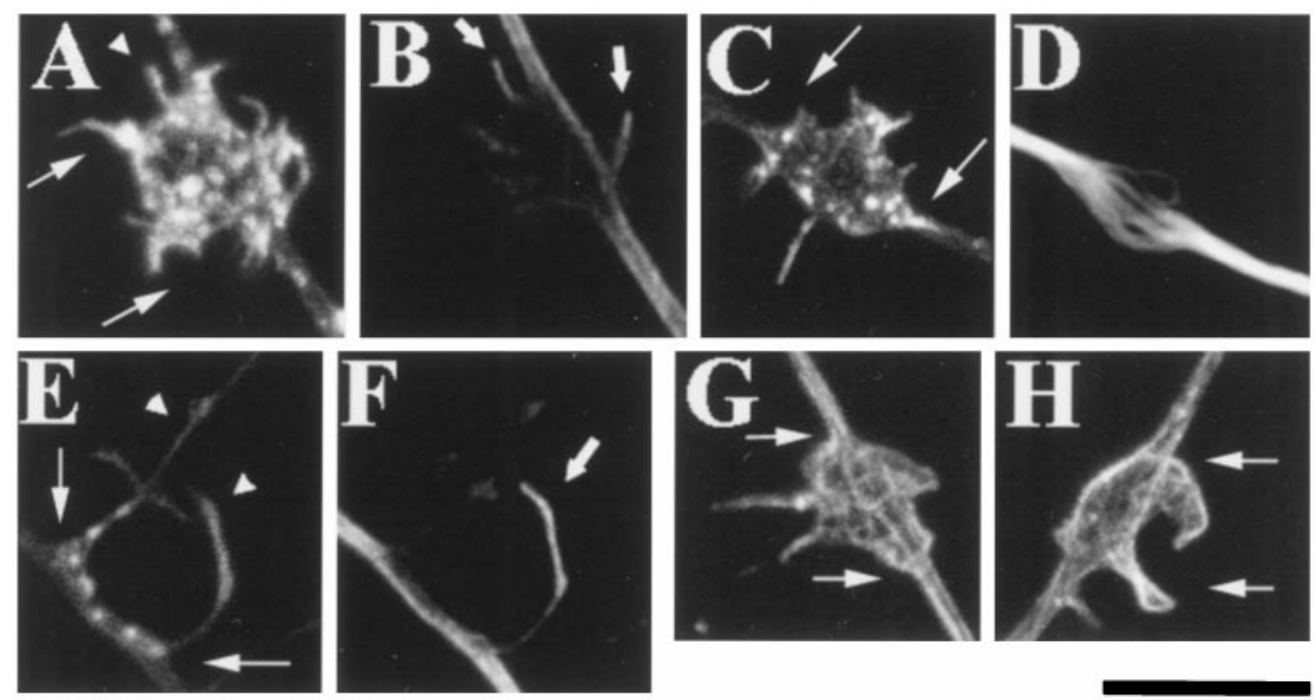

Figure 1. Neurotrophin-coated beads locally induce filopodial sprouting and microtubule rearrangements along axonal shafts. $A, C$, and $E$ are examples of filopodial sprouting (arrowheads) at sites of NGF bead contact with the axon (phalloidin-stained). $A$ and $C$ demonstrate the axonal swelling and formation of F-actin puncta that occurred at sites of bead-axon contact. Although in $A$ and $C$ filopodia were associated mainly with the bead's surface, on occasion filopodia grew from the site of bead contact onto the substratum (arrowhead on left in $E$ ). $B$ and $F$ show microtubule invasion of the filopodial sprouts shown in $A$ and $E$, respectively (arrows). In $E$, a filopodium had grown over the surface of the bead (arrowhead on right) and was invested with a microtubule $(F)$. $D$ shows the localized microtubule debundling (stained with a $\beta$-tubulin antibody) that occurred at sites of axon contact with NGF beads (shown in $C$ ). $G$ and $H$ show lamellae-like sprouting along the surface of the bead in response to BDNF-coated beads. All images were obtained as z-series (6-15 $0.3 \mu \mathrm{m}$ sections) with a Bio-Rad 1024 confocal microscope and projected onto a two-dimensional plane for presentation purposes. Because the beads are translucent, they are not visible in the confocal images, but their location is delineated by the filopodial sprouting response and arrows in $A, C, E, G$, and $H$. Scale bar, $10 \mu \mathrm{m}$.

\begin{tabular}{|c|c|c|}
\hline Type of bead & $\begin{array}{l}\text { Time after bead addition } \\
\text { (hr) }\end{array}$ & $\begin{array}{l}\% \text { Responses } \\
(n)\end{array}$ \\
\hline \multirow[t]{3}{*}{ NGF } & 0.5 & $46(233)$ \\
\hline & 1.0 & $54(294)$ \\
\hline & 3.0 & $71(266)$ \\
\hline $\mathrm{CC}$ & 3.0 & $11(100)$ \\
\hline BSA & 3.0 & $2(94)$ \\
\hline BDNF & 3.0 & $60(127)$ \\
\hline \multicolumn{3}{|l|}{ NGF } \\
\hline$+0.01 \mu \mathrm{g} / \mathrm{ml} \mathrm{CD}$ & 3.0 & $45(228)^{*}$ \\
\hline$+0.05 \mu \mathrm{g} / \mathrm{ml} \mathrm{CD}$ & 3.0 & $33(178)^{*}$ \\
\hline$+0.10 \mu \mathrm{g} / \mathrm{ml} \mathrm{CD}$ & 3.0 & $25(182)^{*}$ \\
\hline$+0.50 \mu \mathrm{g} / \mathrm{ml} \mathrm{CD}$ & 3.0 & $13(178)^{*}$ \\
\hline +1:500 DMSO & 3.0 & $73(258)$ \\
\hline
\end{tabular}

Fisher's exact test (one-tailed) was used to compare experiments with cytochalasin $\mathrm{D}$ (CD) with the DMSO-(vehicle) control. NGF, Nerve growth factor; BDNF, brain-derived neurotrophic factor; CC, cytochrome-C; BSA, bovine serum albumin. BDNF beads were added to BDNF-raised cultures (see Materials and Methods). \% Responses refers to the sprouting of one or more filopodia, or lamellae-like structures, at the bead-axon contact (see Materials and Methods). $n$ refers to the number of bead-axon interactions scored.

$* p<0.0001$.

Live visualization of NGF beads revealed that 50 and $100 \%$ of beads settled on the substratum during the first 10 and $20 \mathrm{~min}$, respectively, after addition to a culture $(n=8$ microscope fields of $1080 \mu \mathrm{m}^{2}$ each for a total of 114 beads), indicating that the response of axons to NGF beads can occur as early as 15-20 min after bead-axon contact.

Actin filament staining revealed that the sprouted axonal filopodia were most often closely associated with the bead surface (Fig. 1A,C). However, in our fixed preparations we also observed filopodia that extended from the axon-bead contact onto the substratum (Fig. $1 E$ ). We therefore sought to determine whether such bead-associated free filopodia could be visualized alive using phase-contrast video microscopy and then compared them with spontaneously formed axonal filopodia, not associated with beads. These observations showed that in response to contact with NGF beads axonal filopodia extended to greater lengths, had longer life-spans, and were generated more frequently than spontaneously formed axonal filopodia. Video sequences of axon-bead contacts showed that in $17 \%$ of interactions $(n=77)$, filopodia extended distances of 10-45 $\mu \mathrm{m}$ from underneath the bead onto either the substratum or into the medium (Fig. 2A). Beadassociated filopodia had longer mean life spans $(8.1 \pm 3.0 \mathrm{~min}$; $n=26)$ than spontaneously generated filopodia $(2.5 \pm 0.4 \mathrm{~min}$; $n=42)(p<0.05$, Welch $t$ test $)$. The mean maximal length attained by bead-associated filopodia was greater than that of spontaneous axonal filopodia $(23.7 \pm 1.7 \mu \mathrm{m}$ and $8.0 \pm 4.1 \mu \mathrm{m}$, respectively; $p<0.0001$, Welch $t$ test). Furthermore, 10 and $92 \%$ of spontaneous and bead-associated filopodia, respectively, extended $15 \mu \mathrm{m}$ or more. Finally, the rate of filopodial formation at sites of bead-axon contact $(0.4+0.2$ filopodia per micrometer per hour) was greater ( $p<0.05$, Welch $t$ test) than at sites not contacting beads $(0.03+0.01$ filopodia per micrometer per hour $)$.

Similar to growth cone filopodia (Gallo et al., 1997), filopodia that extended from the axon and contacted an NGF bead became stabilized ( $20 \mathrm{~min}$ to $>1 \mathrm{hr}$ ) by the bead in $90 \%$ of cases $(n=10)$, regardless of whether they were generated at a site of axon-bead contact or spontaneously from the axonal shaft (Fig. 2B,C). Figure $2 B$ shows one of three cases in which filopodia grew from the axon-associated bead into contact with another bead and were then stabilized. We also observed three cases of spontaneously formed collaterals, which were present before bead addition, that on contact with an NGF bead turned toward it (Fig. 2D), in a 

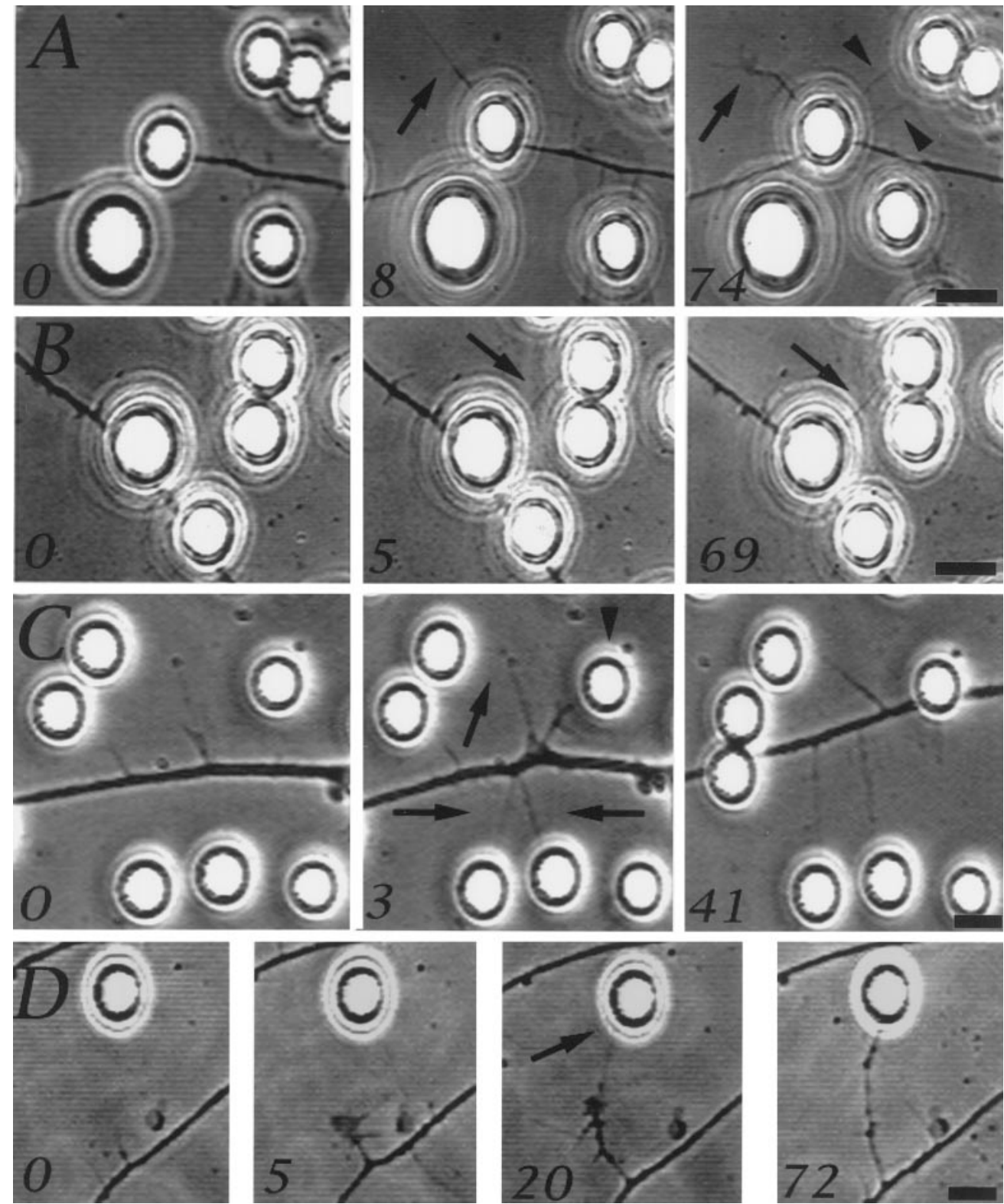

Figure 2. Axonal motile responses at sites of NGF bead contact. Although filopodial sprouts that are formed on the bead surface are not visible using phase-contrast optics, some filopodia extended beyond beads. The numbers in the panels refer to minutes after the first image in the series. $A$ shows a filopodium that extended from the site of axon-bead contact (arrow, 0-8 min) and developed into a collateral branch with a small growth cone-like structure at its tip (arrow, 8-74 min). Two other filopodia also extended from the axon and contacted a nearby bead (arrowheads, 74 min). Filopodia, generated underneath beads, that contacted additional beads became stabilized ( $B$, arrow at 5-69 min). $C$ shows a region of an axon $\sim 50 \mu \mathrm{m}$ behind the growth cone (data not shown) that became spontaneously active, generating filopodia that contacted beads and were stabilized (arrows, 3-41 min). One filopodium thickened as the axon translocated toward the bead it contacted (arrowhead, 3 min), because of the activity of the leading growth cone, and eventually came to rest underneath the bead. Spontaneously formed collateral branches that contacted NGF-coated beads turned and extended toward the beads after initial contact $(D)$. Scale bar, $10 \mu \mathrm{m}$.

manner analogous to that of growth cones (Gallo et al., 1997). Therefore, our observations demonstrate that filopodial sprouts formed at sites of axon-bead contact can interact with additional NGF-coated beads, resulting in both growth of the filopodium toward the bead and the stabilization of the contact.

We also examined whether BDNF-coated beads would produce a similar response from DRG neurons raised in BDNF and hence were responsive to the neurotrophin. BDNF-coated beads also induced the formation of actin-rich structures at sites of bead contact with axons (Table 1). However, in response to BDNFcoated beads, nerve fibers often generated lamellae-like struc- tures (Fig. $1 G, H$ ), in addition to filopodia. Although CC- or BSA-coated beads did attach to DRG axons when added to cultures, these beads did not elicit formation of filopodia (Table 1) or actin accumulation (data not shown). Therefore, both NGF and BDNF are capable of activating actin-dependent motility along axonal shafts. The rest of our studies focused on NGFinduced filopodial sprouting.

\section{The cytoskeleton of axonal filopodial sprouts}

Pretreatment of cultures with cytochalasin D (CD) (Sigma), an inhibitor of actin polymerization, blocked the filopodial sprouting 

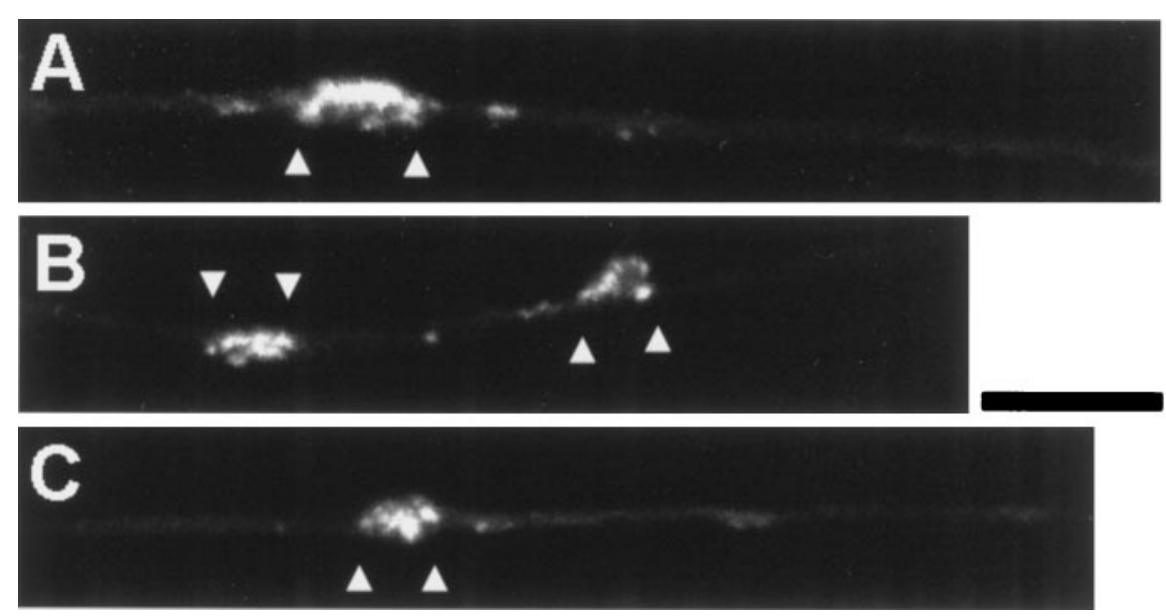

Figure 3. Cytochalasin D prevents NGF-induced filopodial sprouting but not F-actin accumulation at sites of bead-axon contact. Three examples of axons contacting NGF-coated beads (between arrowheads) in the presence of $0.5 \mu \mathrm{g} / \mathrm{ml}$ cytochala$\sin$ D. Note that although the axons are barely visible and show no actin puncta, F-actin staining is prominent at regions of bead contact even in the absence of filopodia or discernible structures. Scale bar, $10 \mu \mathrm{m}$. in a dose-dependent manner (Table 1). Concentrations of CD $>0.5 \mu \mathrm{g} / \mathrm{ml}$ fully blocked the filopodial sprouting underneath beads (data not shown). Interestingly, at $0.5 \mu \mathrm{g} / \mathrm{ml} \mathrm{CD}, 41 \%$ of NGF bead contacts with axons exhibited dense actin patches (Fig. 3 ), even in the absence of filopodial sprouts, suggesting that the beads were still able to elicit the localized polymerization/accumulation of actin but not its reorganization into the filament bundles required for filopodial formation. Indeed, cytochalasins have been shown to only partially inhibit actin polymerization (Bonder and Mooseker, 1986). Therefore, the neurotrophininduced filopodia depend on the dynamic reorganization of the actin cytoskeleton of the axonal shaft.

Visualization of microtubules revealed the reorganization of axonal microtubules at the site of contact with neurotrophincoated beads, including localized debundling of axonal microtubules in $20 \%$ of interactions (Fig. 1D) and the invasion of filopodia by microtubules in $51 \%$ of cases (Fig. $1 B, F)(n=266)$, by $3 \mathrm{hr}$ after bead addition. Microtubule debundling at the sites of bead-axon contact did not occur in cultures treated with concentrations of $\mathrm{CD}$ as low as $0.05 \mu \mathrm{g} / \mathrm{ml}$, suggesting that microtubule debundling requires actin reorganization and filopodial sprouting. Contact of $\mathrm{CC}$ - or BSA-coated beads with axons was never associated with a debundling of microtubules.

To better appreciate the cytoskeletal organization in regions of the axons contacting NGF-coated beads, we investigated the relationship of actin filaments and microtubules to regions of axon-bead contact in confocal z-series using an intersection interval of $0.1 \mu \mathrm{m}$. Figure 4 shows a three-dimensional reconstruction of one such z-series in which a single axonal sprout had grown over the surfaces of two nearby beads. The axonal surface in contact with NGF-coated beads exhibited accumulations of actin filaments (Fig. 4A). Interestingly, in filopodia that contacted beads and contained microtubule(s), F-actin filaments were predominantly on the side of the filopodium contacting the bead, whereas the microtubule(s) was located more externally (Fig. $4 A, B)$. The axonal surface was also rich in actin filaments in regions that had expanded beneath a bead, and these filaments were closely aligned with the substratum (Fig. 4B).

Therefore, NGF-coated beads preferentially cause the polymerization of F-actin at regions of axon-bead contact.

\section{Elaboration of collaterals between NGF beads}

Our video recordings indicate that axonal filopodial sprouts can extend from one NGF bead to another through filopodialmediated contact, thereby resulting in the elaboration of longer collateral branches. To determine whether this might occur, we investigated the associations of NGF-coated beads with collaterals. Figures 4 and 5 show that when several beads were clustered, axonal sprouts extended from bead to bead for distances of up to $60 \mu \mathrm{m}$ or more.

We believe that many of those collateral sprouts were induced by NGF-mediated filopodial sprouting followed by the elongation across 5-15 $\mu \mathrm{m}$ separations between the beads in a manner suggested by our videomicroscopic observations (Fig. 2). However, the association of collaterals with beads may also have resulted from the passive attachment of NGF beads to preexisting collateral branches. To determine whether the longer axon collaterals we observed were simply caused by bead deposition onto preexisting collaterals, we analyzed experiments (four cultures with NGF-coated beads and four cultures with CC-coated beads) in terms of the number of beads contacted by axon collaterals and axons (see Materials and Methods). If NGF beads had not simply deposited onto preexisting collaterals but were actually involved in assisting collateral growth, then the number of beads associated with collaterals should be greater in cultures treated with NGF beads than with CC beads. Furthermore, the percentage of collaterals with NGF beads at their site of formation from the main axon, the collateral's origin, should be greater in the NGF bead than in the CC bead cultures. As shown in Table 2 both of these conditions were met, supporting the hypothesis that NGF beads can assist in the growth of more extensive axon collaterals, if the filopodia can extend from one bead onto another. Further support is obtained from an analysis of the pattern of bead deposition onto the main axons versus the collaterals. These data show that the distribution of NGF beads in contact with collaterals greatly exceeds that expected by the stochastic association of beads that occurs along equivalent lengths of the main axons (Table 2) ( $p<0.001$ and $<0.0001$ for collaterals with lengths of $0-40 \mu \mathrm{m}$ and $0-60 \mu \mathrm{m}$, respectively; $\chi^{2}$ test). The distribution of $\mathrm{CC}$ bead deposition on collaterals is similar to that expected by chance (Table 2) ( $p>0.05$ for collaterals with lengths of $0-40$ $\mu \mathrm{m}$ and $0-60 \mu \mathrm{m} ; \chi^{2}$ test). Equal numbers of CC beads and NGF beads bound to the surfaces of DRG neurons $(2.1 \pm 1.3$ and $1.9 \pm$ 0.9 beads per neuron, respectively; $n=4$ experiments with 74-140 cells counted per experiment), ruling out the possibility that the observed bead distributions were attributable to differential bead attachment to neuronal surfaces. Therefore, in our experiments the analysis of bead distributions indicates that in 

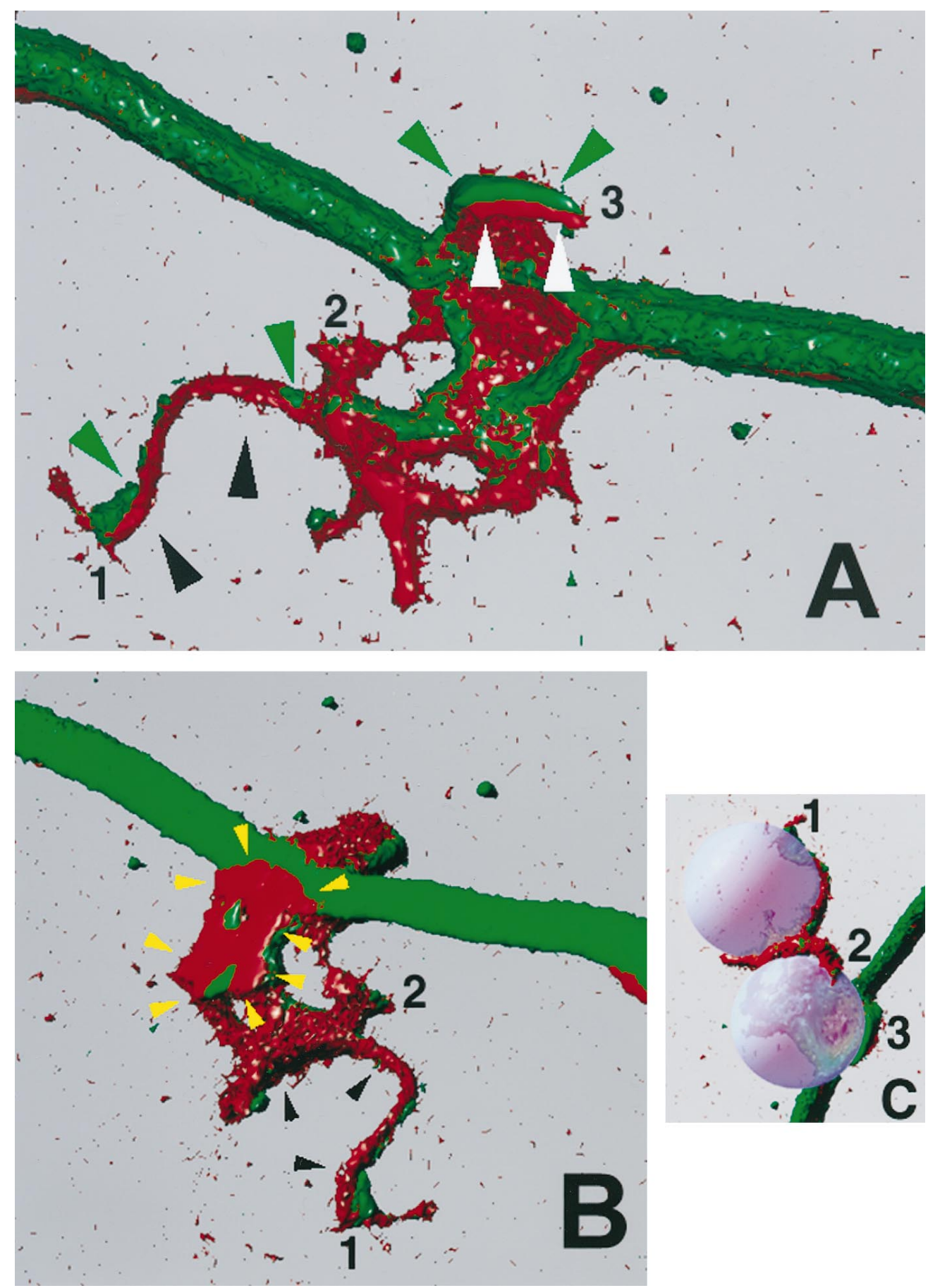

Figure 4. Three-dimensional reconstruction of NGF-induced filopodial sprouts. $A$ (view from above the substratum) and $B$ (view from below the substratum) show three-dimensional reconstructions of the sprouting induced by contact of one axon with two separate beads in series. As with the other confocal images, the beads are not stained and were therefore recreated digitally, and their placement is shown in $C$. The numbers $1-3$ in $A-C$ denote individual filopodia contacting the beads and serve as location markers when the three panels are compared. In all panels, red denotes actin filaments and green represents microtubules. The filopodium growing on the bead that was directly contacting the axon (3) is delineated by white and green arrowheads in $A$, and the filopodium growing on the second bead (1), which was not directly on the axon but rested to the side of the axon shaft, is delineated by black and green arrows. The white $(A)$ and black arrows $(A, B)$ denote the surface of the filopodium that was in contact with the bead. Note that the surface of the filopodium that contacted the bead is rich in actin filaments $(\mathrm{red})$. The green arrows point to microtubules that invaded the sprout. Note that the microtubules are more external than the actin with regard the surface of bead-axon interface. In $B$, the yellow arrows outline a portion of the axonal spouting that came to rest underneath the bead closest to the axon. Note that this region is rich in actin and also closely apposed to the substratum. Filopodium number 1 had grown a distance of $\sim 20 \mu \mathrm{m}$ over the surfaces of the beads. This image was created using Image Volumes v. 2.1 (Minnesota Datametrics, Minneapolis, MN) and a z-series of 56 confocal images (Bio-Rad 1024) obtained using a voxel size of $0.1 \mu \mathrm{m}$. 

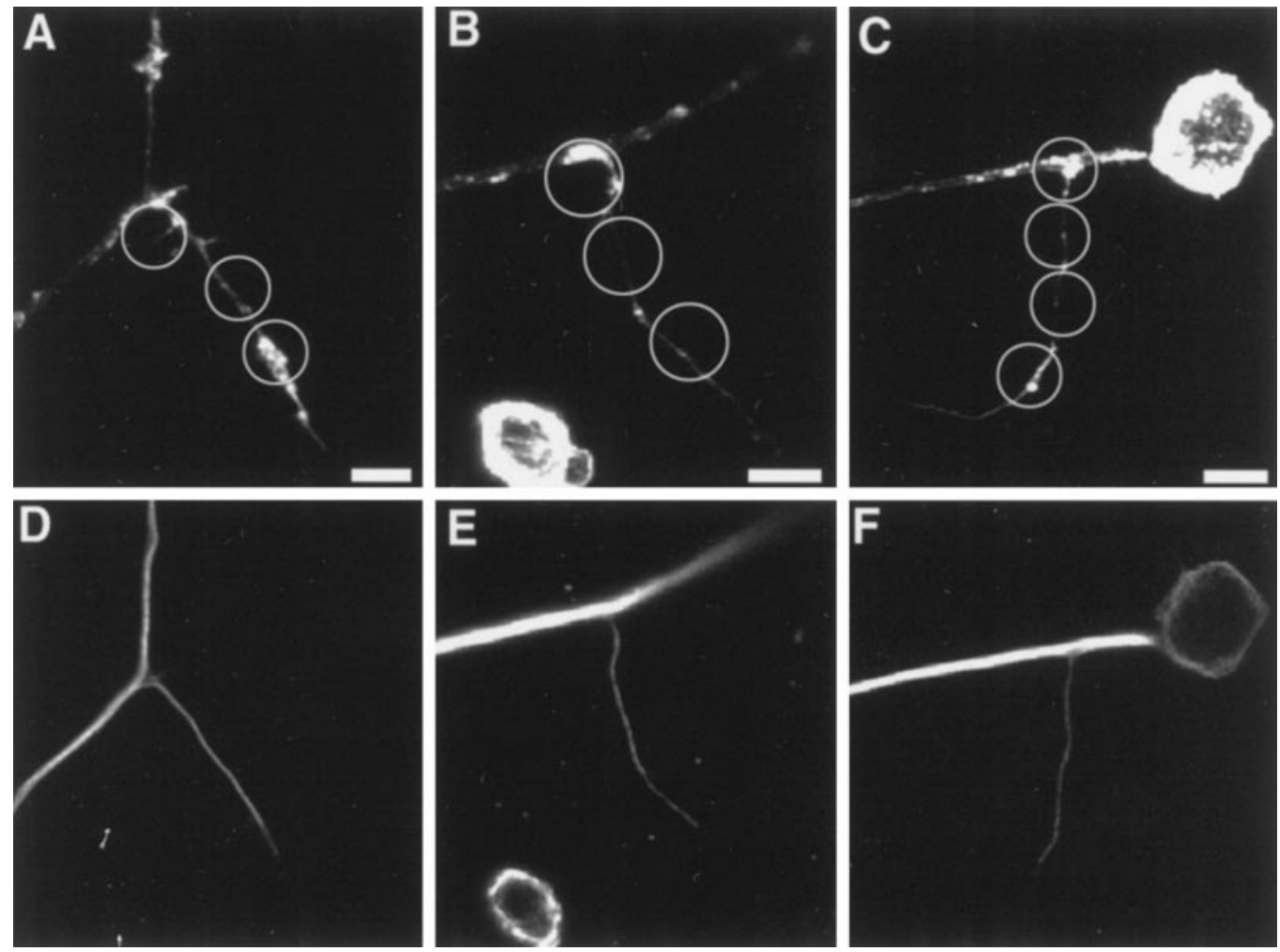

Figure 5. Examples of collateral branches formed at sites where multiple NGF-coated beads were in close apposition. In all panels the position of the NGF-coated beads is indicated by the white circles. $A-C$ represent rhodamine phalloidin staining of F-actin and $(D, E)$ microtubule staining of the same cells. $B$ and $E$ and $C$ and $F$ are collateral branches that formed within $100 \mu \mathrm{m}$ of the cell body (visible in $C$ and $F$ ); in $B$ and $E$ the axon to the right of the collateral sprout was raised above the substratum and therefore appears out of focus. Scale bar, $10 \mu \mathrm{m}$.

Table 2. Frequency distribution of bead association with collateral branches

\begin{tabular}{|c|c|c|c|c|c|c|c|}
\hline \multirow{2}{*}{$\begin{array}{l}\text { Bead and neurite } \\
\text { type }(n)\end{array}$} & \multirow{2}{*}{$\begin{array}{l}\% \text { Collaterals with } \\
\text { bead at origin }\end{array}$} & \multicolumn{6}{|c|}{$\%$ Collaterals with $n$ beads along neurite } \\
\hline & & 1 & 2 & 3 & 4 & 5 & 6 \\
\hline NGF beads (147) & 46 & & & & & & \\
\hline \multicolumn{8}{|l|}{ Collateral length } \\
\hline $40 \mu \mathrm{m}(55)$ & & 24 & 31 & 31 & 12 & 2 & 0 \\
\hline $60 \mu \mathrm{m}(13)$ & & 7 & 15 & 8 & 15 & 39 & 16 \\
\hline \multicolumn{8}{|c|}{ Main axon segment } \\
\hline $40 \mu \mathrm{m}(146)$ & & 49 & 38 & 10 & 3 & 0 & 0 \\
\hline $60 \mu \mathrm{m}(146)$ & & 27 & 32 & 28 & 11 & 2 & 0 \\
\hline CC beads (116) & 7 & & & & & & \\
\hline \multicolumn{8}{|l|}{ Collateral length } \\
\hline $40 \mu \mathrm{m}(60)$ & & 65 & 22 & 10 & 3 & 0 & 0 \\
\hline $60 \mu \mathrm{m}(17)$ & & 46 & 25 & 23 & 6 & 0 & 0 \\
\hline
\end{tabular}

Rows provide data by the bead and neurite (axon or collateral) type involved in the interactions. Columns provide information regarding the number of beads associated with equivalent lengths of neurites under the given experimental condition. Similar numbers of collaterals were sampled across experimental conditions and therefore do not reflect relative rates of collateral formation. See Materials and Methods for details on the sampling procedures. NGF, Nerve growth factor; CC, cytochrome C.

some cases at least $60 \mu \mathrm{m}$ of axon collateral could be elaborated through multiple NGF-coated bead contacts during a $3 \mathrm{hr}$ period.

\section{Signal transduction of the NGF signal that induces axonal filopodial sprouting}

Role of NGF receptors

The response of nerve fibers to NGF-coated beads appears to be mediated by the high-affinity NGF receptor (Kaplan et al., 1991; Heumann, 1994; Kaplan and Stephens, 1994; Barbacid, 1995) tyrosine receptor kinase A (trkA), as indicated by the inhibition of the response by an antibody against the extracellular domain of the receptor (Table 3) (Gallo et al., 1997; Oakley et al., 1997). Furthermore, soluble NGF concentrations that saturate the trkA receptor (10 ng/ml NGF), but not the low-affinity panneurotrophin receptor (p75), also prevented the response (Table 3); $100 \mathrm{ng} / \mathrm{ml} \mathrm{NGF}$ had no greater effect than $10 \mathrm{ng} / \mathrm{ml} \mathrm{NGF}$ (Table 3). We also used 100 nm k252a (Biomol Research Laboratories, Plymouth Meeting, PA) to inhibit the autophosphorylation of trkA in response to NGF binding (Koizumi et al., 1988; Berg et al., 1992; Muroya et al., 1992; Nye et al., 1992; Tapley et 


\begin{tabular}{ll}
\hline Table 3. TrkA involvement in the axonal response to NGF-coated beads \\
\begin{tabular}{ll} 
Treatment & $\%$ Filopodial responses $(n)$ \\
\hline No treatment & $71(266)$ \\
$25 \mu \mathrm{g} / \mathrm{ml} \mathrm{trkA}$ antibody & $20(128)^{*}$ \\
$10 \mathrm{ng} / \mathrm{ml} \mathrm{NGF}$ & $29(211)^{*}$ \\
$100 \mathrm{ng} / \mathrm{ml} \mathrm{NGF}$ & $32(142)^{*}$ \\
$100 \mathrm{ng} / \mathrm{ml} \mathrm{BDNF}$ & $67(267)^{* *}$ \\
$70 \mu \mathrm{g} / \mathrm{ml} \mathrm{p75}$ antibody & $68(241)^{* *}$ \\
$100 \mathrm{nM} \mathrm{k252a}$ & $19(127)^{*}$
\end{tabular}
\end{tabular}

Determination of axonal responses to NGF-coated bead contact was performed $3 \mathrm{hr}$ after addition of beads to the culture. In the above experiments, cultures had been pretreated for a period of $1 \mathrm{hr}$ before bead addition. Fisher's exact test (one-tailed) was used to compare data from each experiment with the no treatment group, with the exception of the k252a experiment, which was compared with the DMSO-treated control (see Table 1). $n$ refers to the number of bead-axon interactions scored. ${ }^{*} p<0.0001 ;{ }^{*} p<0.4$.

al., 1992). K252a (100 nM) greatly reduced the axonal sprouting response to NGF-coated beads (Table 3), providing further evidence for trkA involvement.

Because the $\mathrm{p} 75$ receptor has a role in the turning response of DRG growth cones toward NGF-coated beads (Gallo et al., 1997), we investigated its involvement in the axonal sprouting response to contact with NGF-coated beads. To interfere with NGF binding to the p75 receptors, we applied the Chex antibody to the extracellular domain of p75 to cultures at concentrations previously shown to fully block NGF binding to p75 (Weskamp and Reichardt, 1991). Chex treatment had no effect on the axonal response (Table 3), although the same concentrations of Chex affected the ability of DRG growth cones to turn toward NGFcoated beads (Gallo et al., 1997). Similarly, the addition of 100 $\mathrm{ng} / \mathrm{ml} \mathrm{BDNF}$ to the culture medium, which saturates p75 receptors and decreases the $\mathrm{p} 75$-mediated facilitation of trkA receptor activation (Barker and Shooter, 1994), did not affect the filopodial sprouting response (Table 3). In a manner similar to that of the Chex antibody, this treatment was also previously shown to partially block growth cone turning toward NGF-coated beads (Gallo et al., 1997). Therefore, the axonal response to NGF-coated beads appears not to require NGF binding to the p75 receptor.

\section{Role of kinases}

Protein phosphorylation has been suggested to be involved in filopodial extension (Wu and Goldberg, 1993; Wu et al., 1996). We therefore investigated the role of protein kinases in the axonal filopodial response, using a pharmacological approach. Unless specified otherwise, for all kinase inhibitor studies the cultures were pretreated with a drug for $1 \mathrm{hr}$; NGF-coated beads were then added and the cultures were fixed after $3 \mathrm{hr}$. The kinase inhibitor KT5926 (Biomol Research Laboratories), which is structurally related to $\mathrm{k} 252 \mathrm{a}$, also inhibited the response (Table 4), albeit to a lesser degree than $\mathrm{k} 252 \mathrm{a}$, even at a dose fivefold greater. Although KT5926 does not inhibit trkA autophosphorylation, it affects a similar set of other kinases as does k252a (Hashimoto et al., 1991), suggesting that additional kinases are also involved in the response, possibly $\mathrm{Ca}^{2+} /$ calmodulindependent protein kinase II and/or myosin light chain kinase (Nakanishi et al., 1990; Hashimoto et al., 1991). Because the effects of KT5926 confound the interpretation of the effects of $\mathrm{k} 252 \mathrm{a}$ on trkA autophosphorylation, we investigated whether a shorter term exposure might differentiate the effects of the two drugs. To do this, we coadministered the drugs with the beads and
Table 4. The role of kinases in the axonal response to NGF-coated beads

\begin{tabular}{|c|c|c|}
\hline Treatment & Protocol & $\%$ Filopodial responses $(n)$ \\
\hline 100 nм k252a & 1 & $19(127)^{*}$ \\
\hline 100 nм КТ5926 & 1 & $43(126)^{*}$ \\
\hline 500 пм КТ5926 & 1 & $30(178)^{*}$ \\
\hline $100 \mathrm{~nm} \mathrm{k} 252 \mathrm{a}$ & 2 & $30(168)^{* *, * * *}$ \\
\hline 100 nм КТ5926 & 2 & $59(181)^{* *, * * * *}$ \\
\hline 1:500 DMSO & 2 & $52(107)$ \\
\hline $50 \mathrm{nM}$ wortmannin & 1 & $51(147)^{*}$ \\
\hline $100 \mathrm{~nm}$ wortmannin & 1 & $26(133)^{*}$ \\
\hline $10 \mu \mathrm{M}$ LY294002 & 1 & $47(217)^{*}$ \\
\hline $50 \mu \mathrm{M}$ LY294002 & 1 & $43(152)^{*}$ \\
\hline $100 \mu \mathrm{M}$ LY294002 & 1 & $34(188)^{*}$ \\
\hline
\end{tabular}

Protocol 1: Drug was added to the culture $1 \mathrm{hr}$ before the introduction of beads, and cells were fixed $3 \mathrm{hr}$ later. Protocol 2: Drug and beads were coadministered, and cells were fixed 30 min later. Data on DMSO controls $(3 \mathrm{hr})$ are presented in Table 1. Fischer's exact test (one-tailed) was used to compare results obtained using protocol 1 with DMSO controls, and results obtained using protocol 2 were compared with each other and with the $30 \mathrm{~min}$ DMSO control. $n$ refers to the number of bead-axon interactions scored.

${ }^{*} p<0.0001 ; * * p<0.0001 ; * * * p<0.0002 ; * * * * p>0.15$.

fixed the cultures $1 \mathrm{hr}$ later. In this experimental paradigm, k252a still blocked the response (Table 4), whereas KT5926 had no effect (Table 4), suggesting that KT5926 is affecting processes downstream of trkA autophosphorylation that occur on an extended time frame.

PI-3 kinase has been shown to be involved in the transduction of NGF signals mediating nerve fiber growth (Kimura et al., 1994; Rodriguez-Viciana et al., 1994; Jackson et al., 1996) and retinal neurite outgrowth (Lavie et al., 1997) and in the signaling pathways of other growth factors (Chung et al., 1994; Ninomiya et al., 1994). Furthermore, PI-3 kinase is involved in the production of membrane ruffling in response to growth factor receptor activation in non-neuronal cells (Kotani et al., 1994; Ridley, 1994; Wennstrom et al., 1994; Kotani et al., 1995; Thomas et al., 1997). Therefore, using a pharmacological approach, we investigated whether PI-3 kinase could mediate aspects of the axonal response to contact with NGF-coated beads. Wortmannin (Calbiochem, La Jolla, CA) blocks PI-3 kinase activity at low nanomolar concentrations without affecting other targets of the drug until in the micromolar range (Ui et al., 1995). Both 50 and 100 nM wortmannin decreased and inhibited the nerve fiber response (Table 4), respectively. We also investigated the effects of another PI-3 kinase inhibitor (LY294002; Calbiochem), which is molecularly distinct from wortmannin and exhibits a high degree of specificity for PI-3 kinase (Cheatham et al., 1994; Vlahos et al., 1994). LY294002 (10-100 $\mu \mathrm{M})$ inhibited the axonal filopodial response to NGF-coated beads (Table 4).

Inhibition of the response by drugs that affect PI-3 kinase lowered the response to a $30-40 \%$ level (Table 4). For the following reasons, we believe this reflects a nearly full inhibition of the NGF-induced filopodial sprouting. As discussed previously, DRG axons on fibronectin spontaneously generate $0.03 \pm$ 0.01 filopodia per micrometer per hour. Assuming that the contact of the bead with an axon entails a region equal to approximately half of the bead's diameter (i.e., $5 \mu \mathrm{m}$ ) of the axonal surface, this means that on the average approximately 0.15 filopodia will spontaneously form during a $1 \mathrm{hr}$ contact with a bead. In this and previous work (Gallo et al., 1997), we have shown that NGF-coated beads are capable of stabilizing filopodia that con- 


\begin{tabular}{|c|c|c|}
\hline Treatment & Protocol & \% Filopodial responses $(n)$ \\
\hline Saline & 1 & $73(159)$ \\
\hline \multicolumn{3}{|l|}{$\mathrm{Ca}^{2+}$-free saline } \\
\hline$+1 \mathrm{~mm}$ EGTA & 1 & $83(184)$ \\
\hline$+1 \mu \mathrm{M} \mathrm{TH}$ & 1 & $81(133)^{*}$ \\
\hline$+10 \mu \mathrm{M}$ RY & 1 & $82(146)^{*}$ \\
\hline$+5 \mu \mathrm{M} \mathrm{IO}$ & 1 & $76(128)^{* *}$ \\
\hline$+1 \mu \mathrm{M}$ TH and $10 \mu \mathrm{M}$ RY & 1 & $79(167)^{* *}$ \\
\hline$+1 \mu \mathrm{M} \mathrm{TH}$ and $5 \mu \mathrm{M} \mathrm{IO}$ & 2 & $63(173)^{* *}$ \\
\hline$+5 \mu \mathrm{M}$ IO and $10 \mu \mathrm{M}$ RY & 1 & $75(181)^{* *}$ \\
\hline +1:500 DMSO & 1 & $71(191)$ \\
\hline +1:500 DMSO & 2 & $62(184)$ \\
\hline
\end{tabular}

Protocol 1: The culture medium was changed to either saline or $\mathrm{Ca}^{2+}$-free saline containing drugs $2 \mathrm{hr}$ before the introduction of beads, and cells were fixed $3 \mathrm{hr}$ later. Protocol 2: The culture medium was changed to $\mathrm{Ca}^{2+}$-free saline $2 \mathrm{hr}$ before bead addition; thapsigargin ( $\mathrm{TH}$ ) and ionomycin (IO) were added $20 \mathrm{~min}$ before the beads. Cells were fixed $1 \mathrm{hr}$ later. The Fischer's exact test (one-tailed) was used to compare experimental results from experiments using drugs with the DMSO controls within experimental protocol, and the two-tailed test was used to compare the saline versus the $\mathrm{Ca}^{2+}$-free + EGTA saline results $(p, 0.025)$. RY, Ryanodine. $n$ refers to the number of bead-axon interactions scored.

${ }^{*} p<0.05 ; * * p>0.05$.

tact them. Therefore, after a $3 \mathrm{hr}$ contact period we would expect that $\sim 30-40 \%$ of beads would have stabilized a spontaneously generated axonal filopodium. However, this is likely an overestimation, because for a filopodium to contact the bead surface it may have to extend above the substratum, and we determined that $41 \%$ of spontaneously generated axonal filopodia $(n=56)$ extended above the substratum. We therefore expect that under conditions that block NGF-mediated filopodial sprouting, we would still observe $15-40 \%$ of axonal contacts with NGF beads having one filopodium associated with them. As further evidence of the effectiveness of wortmannin and LY29002, 95 and $90 \%$ of the responses to NGF-coated beads in the presence of $50 \mu \mathrm{M}$ LY294002 and $100 \mathrm{~nm}$ wortmannin, respectively, exhibited only one filopodium, in striking contrast to the more robust responses to NGF beads in control conditions (DMSO) when only $17 \%$ of the responses exhibited a single filopodium. Also, in the presence of PI-3 kinase inhibitors, axons did not form swollen axonal regions with actin puncta (Fig. $1 A, C$ ), a hallmark of a robust NGF bead axonal response. Hence, our data support the hypothesis that PI-3 kinase and phosphoinositides are involved in transducing the NGF signal that triggers the sprouting of axonal filopodia and cytoskeletal reorganization.

\section{Role of $\mathrm{Ca}^{2+}$ fluxes}

Experimentally induced transient elevation of cytoplasmic $\mathrm{Ca}^{2+}$ has been shown to regulate filopodial extension both at growth cones (Davenport and Kater, 1992) and along nerve fiber shafts (Williams et al., 1995; Ziv and Spira, 1997). NGF can mediate increases in cytoplasmic $\mathrm{Ca}^{2+}$ concentration (De Bernardi et al., 1996; Jian et al., 1997). Therefore, we investigated the involvement of cytoplasmic $\left[\mathrm{Ca}^{2+}\right]$ in the induction of filopodial sprouts by NGF-coated beads. These experiments were performed by changing the culture medium to a simplified saline solution either containing $2 \mathrm{mM} \mathrm{Ca}^{2+}$ or lacking $\mathrm{Ca}^{2+}$ and containing $1 \mathrm{~mm}$ EGTA to chelate any extracellular available $\mathrm{Ca}^{2+}$, as used previously by our laboratory (Gomez et al., 1995). Even in the absence of extracellular $\mathrm{Ca}^{2+}$, axonal shafts sprouted filopodia at contacts with NGF-coated beads (Table 5), indicating that $\mathrm{Ca}^{2+}$ influx into the axon is not required for the bead-associated response. To investigate the possible role of intracellular $\mathrm{Ca}^{2+}$ stores, we pretreated the cultures with $\mathrm{Ca}^{2+}$-free saline containing EGTA and $1 \mu \mathrm{M}$ thapsigargin (TH) (Calbiochem), $10 \mu \mathrm{M}$ ryanodine (Calbiochem), or $5 \mu \mathrm{M}$ ionomycin (IO) (Sigma), or combinations of these agents. Previous studies from our lab demonstrated that DRG neurons contain intracellular stores sensitive to these drugs (Gomez et al., 1995) and that these concentrations of the pharmacological agents deplete each store independently. Significantly, in $\mathrm{Ca}^{2+}$-free saline, growth cones were often collapsed by the time the cultures were fixed, and in all experiments in which two drugs were coadministered, most growth cones were collapsed (data not shown), showing that our treatments affected DRG growth cone morphology, which is dependent on $\mathrm{Ca}^{2+}$ levels (Lankford and Letourneau, 1989, 1991). Hence, the collapse of growth cones in response to our treatments served as a positive control for the efficacy of our treatments aimed at affecting $\mathrm{Ca}^{2+}$ levels in DRG cells. However, neither individual drug treatments nor combinations of the drugs inhibited the axonal sprouting response to NGF-coated beads (Table 5), whereas some treatments caused slight increases in the response. The combination of $\mathrm{TH}$ and $\mathrm{IO}$ appeared to be toxic to both neurons and non-neuronal cells, when cells were fixed $3 \mathrm{hr}$ after addition of the beads. Therefore, we used shorter preincubation times with the drugs (protocol 2, Table 5) and fixed cells $1 \mathrm{hr}$ after addition of beads. This protocol was not toxic to neurons and did not inhibit the sprouting response (Table 5). Simultaneous administration of all three agents was toxic to neurons. These results indicate that neither $\mathrm{Ca}^{2+}$ influx nor release of $\mathrm{Ca}^{2+}$ from intracellular stores is required for filopodial sprouting and initiation of axon collateral branch formation when NGF-coated beads contact axons.

\section{DISCUSSION}

This report demonstrates that neurotrophins can locally activate actin-dependent filopodial sprouting along axonal shafts, resulting in the initiation and elaboration of collateral branches. The present results are particularly significant because both in vivo and in vitro axonal shafts are generally quiescent and do not exhibit much protrusive motility. Actin filaments form a cortical meshwork beneath the axonal plasmalemma (Letourneau, 1983), and our data show that neurotrophin signaling can induce polymerization and reorganization of this quiescent actin filament network through the activation of trkA receptors and indicate subsequent signal transduction through a PI-3 kinase-dependent pathway. Of great significance, the filopodial sprouts that formed at sites of bead contact with axons could become invested with microtubules, thereby showing that these responses to bead contacts contained both of the cytoskeletal components required of collateral branches. Changes in the concentration of cytoplasmic $\mathrm{Ca}^{2+}$ do not appear to mediate this NGF-induced filopodial sprouting along sensory axonal shafts. Prolonged treatment with KT5926 inhibited the filopodial response, suggesting that additional protein kinases may be involved in the induction or maintenance of axonal filopodia.

Filopodia that sprout in response to single beads do not usually grow past the bead. These sprouts were observed to extend over as much as half of the bead's circumference (e.g., $\sim 15 \mu \mathrm{m}$ ) and are similar in length to those observed in some in vivo (Kaethner and Stuermer, 1992; Halloran and Kalil, 1994; Witte et al., 1996) and in vitro systems (Sato et al., 1994). However, filopodial sprouts can grow from one bead to another, if the beads are close to one 
another (Figs. 2, 4, 5; Table 2), allowing the formation of neuritic sprouts with a morphology similar to that of longer collateral branches in vivo.

The filopodia that formed at the sites of axon contact with NGF-coated beads were rich in actin, and their formation often coincided with a debundling of the axonal microtubules. Because treatment with CD prevented the axonal debundling, reorganization of actin filaments appears to be required for the restructuring of the axonal microtubule bundle. The fact that microtubules were found within bead-induced filopodia suggests that a hallmark of nerve fiber growth, the invasion of actin-rich structures by microtubules (Theriot and Mitchison, 1991; Bentley and O'Connor, 1994; Lin et al., 1994; Tanaka and Sabry, 1995; Challacombe et al., 1996), occurs at sites of axon-bead interaction. Our observations of the distribution of actin filaments at sites of axon-bead contact in three-dimensional reconstructions are consistent with a localized activation of NGF receptors resulting in the spatially restricted polymerization of actin filaments. Preexisting axonal microtubule ends may be captured by these actin structures (Gordon-Weeks, 1991) and transported into nascent axonal filopodia, as suggested by Yu et al. (1994). Alternatively, polymerization of new microtubules using the ends of preexisting or severed axonal microtubules as seeds may occur.

Localized swelling of the axon and a concomitant debundling of the axonal microtubule array may reflect the mechanism by which DRG neurons produce axon collaterals during development in vivo. NGF treatment of developing embryos potentiates DRG collateral sprouting in the spinal cord (Zhang et al., 1994), suggesting a role for NGF in DRG axon branching during development. Consistent with our findings, Ozaki and Snider (1997) report that DRG axon collateral formation in the spinal cord is preceded by a localized swelling of the axon, which subsequently gives rise to a branch.

To our knowledge, the data presented in this manuscript are the first investigation of the role of second messenger systems in the generation of axon collateral branches in response to defined extrinsic cues. PI-3 kinase has been shown previously to be involved in the activation of surface motility in various cell types (Kotani et al., 1994; Ridley, 1994; Wennstrom et al., 1994; Kotani et al., 1995; Thomas et al., 1997), and we now provide pharmacological data suggesting that neurotrophin-mediated activation of axon collateral sprouting uses the PI-3 kinase pathway. However, although at the concentrations used in our studies wortmannin and LY294002 have been reported to greatly inhibit PI-3K kinase, we cannot exclude the possibility that the drugs inhibited additional targets. GTPases (rho, rac, and $\mathrm{Cdc} 4$ ) have been shown to be involved in filopodial formation in non-neuronal cells (Tapon and Hall, 1997), and recent evidence suggests that they are involved in aspects of growth cone behavior (Luo et al., 1997). Although GTPases may interact with PI-3 kinase pathways (Zhang et al., 1993; Reif et al., 1996; Zheng et al., 1996), their possible role in PI-3 kinase-mediated axon collateral initiation remains to be studied. Work from other laboratories has shown that experimentally induced increases in intracellular $\mathrm{Ca}^{2+}$ can initiate axonal filopodia sprouting (Williams et al., 1995) and collateral branches (Ziv and Spira, 1997). However, we found no evidence for $\mathrm{Ca}^{2+}$ involvement in NGF-mediated collateral sprouting.

Comparison of collateral branch formation by the same neurons in vitro and in vivo (Bastmeyer and O'Leary, 1996) suggests that factors that stimulate the initiation of collateral branches are distinct from additional factors that stabilize collaterals and allow them to mature. Our data clearly indicate that neurotrophins can locally induce the initiation of collateral branches (i.e., the formation of axonal filopodia), resulting in sprouts containing the major cytoskeletal components of axons: actin filaments and microtubules. Furthermore, our observations also show that nerve growth factor can stabilize axonal filopodia, providing evidence that neurotrophins may stabilize as well as initiate extending collateral branches. When several NGF beads were present in close apposition, axonal filopodial sprouts extended from one NGF-coated bead to another, thereby elaborating more extensive axon collaterals. In vivo axon collateral branches my be initiated by localized sources of neurotrophin, such as a neighboring cell or NGF locally associated with the extracellular matrix. After the initial neurotrophin-mediated sprouting, the extending collateral branch could then interact with additional sources of neurotrophin, or additional cues, and continue extending.

In conclusion, our results identify neurotrophins as molecules that can both initiate and stabilize collateral branching and provide an in vitro system for the investigation of the cytoskeletal mechanisms underlying the regulation of collateral branch formation by extracellular cues. Significantly, our findings of the direct effects of neurotrophins on axonal shaft motility indicate that the previously reported effects of neurotrophins on axonal arborizations in vivo (Schnell et al., 1994; Zhang et al., 1994; Cohen-Corey and Fraser, 1995; Sawai et al., 1996; Inoue and Sanes, 1997) may be attributable to the direct and local effects of neurotrophins on the axonal cytoskeleton and not through indirect signaling mechanisms, such as changes in the membrane properties of other cells, as has been shown previously (Schwegler et al., 1995; Castellani and Bolz, 1997). Furthermore, our model system provides a way to locally activate the polymerization and reorganization of the actin cytoskeleton and will be useful in studying the mechanisms underlying such cytoskeletal regulation.

\section{REFERENCES}

Barbacid M (1995) Neurotrophic factors and their receptors. Curr Opin Cell Biol 7:148-155.

Barker PA, Shooter EM (1994) Disruption of NGF binding to the low affinity neurotrophin receptor $\mathrm{p} 75^{\mathrm{LNTR}}$ reduces NGF binding to trkA on PC12 cells. Neuron 13:203-215.

Bastmeyer M, O'Leary DDM (1996) Dynamics of target recognition by interstitial axon branching along developing cortical axons. J Neurosci 16:1450-1459.

Bentley D, O'Connor TP (1994) Cytoskeletal events in growth cone steering. Curr Opin Neurobiol 4:43-48.

Bentley D, Toroian-Raymond A (1986) Disoriented pathfinding by pioneer neurone growth cones deprived of filopodia by cytochalasin treatment. Nature 323:712-715.

Berg MM, Sternberg DW, Parada LF, Chao MV (1992) k252a inhibits nerve growth factor induced trk proto-oncogene tyrosine phosphorylation and kinase activity. J Biol Chem 267:13-16.

Bhide PG, Frost DO (1991) Stages of growth of hamster retinofugal axons: implications for developing axonal pathways with multiple targets. J Neurosci 11:485-504.

Bonder EM, Mooseker MS (1986) Cytochalasin B slows but does not prevent monomer addition at the barbed end of the actin filament. J Cell Biol 102:282-288.

Castellani V, Bolz J (1997) Membrane-associated molecules regulate the formation of layer-specific cortical circuits. Proc Natl Acad Sci USA 94:7030-7035.

Challacombe JF, Snow DM, Letourneau PC (1996) Role of the cytoskeleton in growth cone motility and axonal elongation. Semin Neurosci 8:67-80.

Cheatham B, Vlahos CJ, Cheatham L, Wang L, Blenis J, Kahn CR (1994) Phosphatidylinositol 3-kinase activation is required for insulin stimulation of pp70 S6 kinase DNA synthesis, and glucose transporter translocation. Mol Cell Biol 14:4902-4911.

Chien C, Rosenthal DE, Harris WA, Holt CE (1993) Navigational errors 
made by growth cones without filopodia in embryonic Xenopus brain. Neuron 11:237-251.

Chung J, Grammer TC, Lemon KP, Kazlauskas A, Blenis J (1994) PDGF- and insulin-dependent pp70 ${ }^{\text {s6k }}$ activation mediated by phosphatidylinositol-3-OH kinase. Nature 370:71-75.

Cohen-Cory S, Fraser SE (1995) Effects of brain-derived neurotrophic factor on optic axon branching and remodelling in vivo. Nature 378:192-196.

Connolly JL, Seeley PJ, Greene LA (1985) Regulation of growth cones morphology by nerve growth factor: a comparative study by scanning electron microscopy. J Neurosci Res 13:183-198.

Davenport RW, Kater SB (1992) Local increases in intracellular calcium elicit local filopodial responses in helisome neuronal growth cones. Neuron 9:405-416.

De Bernardi MA, Rabin SJ, Colangelo AM, Brooker G, Mocchetti I (1996) TrkA mediates the nerve growth factor-induced intracellular calcium accumulation. J Biol Chem 271:6092-6098.

Devor M, Schonfeld D, Seltzer Z, Wall PD (1979) Two modes of cutaneous reinnervation following peripheral nerve injury. J Comp Neurol 185:211-220.

Diamond J, Coughlin M, Macintyre L, Holmes M, Visheau B (1987) Evidence that endogenous $\beta$ nerve growth factor is responsible for the collateral sprouting, but not the regeneration, of nociceptive axons in adult rats. Proc Natl Acad Sci USA 84:6596-6600.

Diamond J, Holmes M, Coughlin M (1992) Endogenous NGF and nerve impulses regulate the collateral sprouting of sensory axons in the skin of the adult rat. J Neurosci 12:1454-1466.

Doubleday B, Robinson PP (1992) The role of nerve growth factor in collateral reinnervation by cutaneous $\mathrm{C}$-fibers in the rat. Brain Res 593:179-184.

Doucette R, Diamond J (1987) Normal and precocious sprouting of heat nociceptors in the skin of adult rats. J Comp Neurol 261:592-603.

Gallo G, Lefcort FB, Letourneau PC (1997) The trkA receptor mediates growth cone turning toward a localized source of nerve growth factor. J Neurosci 17:5445-5454.

Ghosh A, Shatz CJ (1992) Pathfinding and target selection by developing geniculocortical axons. J Neurosci 12:39-55.

Gloster A, Diamond J (1992) Sympathetic nerves in adult rats regenerate normally and restore function during an anti-NGF treatment that prevents their collateral sprouting. J Comp Neurol 326:363-374.

Gomez TM, Letourneau PC (1994) Filopodia initiate choices made by sensory neuron growth cones at laminin/fibronectin borders in vitro. J Neurosci 14:5959-5972.

Gomez TM, Snow DM, Letourneau PC (1995) Characterization of spontaneous calcium transients in nerve growth cones and their effect on growth cone migration. Neuron 14:1233-1246.

Gordon-Weeks PR (1991) Evidence for microtubule capture by filopodial actin filaments in growth cones. NeuroReport 2:573-576.

Gundersen RW, Barrett JN (1980) Characterization of the turning response of dorsal root neurites toward nerve growth factor. J Cell Biol 87:546-554.

Halloran MC, Kalil K (1994) Dynamic behaviors of growth cones extending in the corpus callosum of living cortical brain slices observed with video microscopy. J Neurosci 14:2161-2177.

Hashimoto Y, Nakayama T, Teramoto T, Kato H, Watanabe T, Kinoshita M, Tsukamoto K, Tokunaga K, Kurokawa K, Nakanishi S (1991) Potent and preferential inhibition of $\mathrm{Ca}^{++} /$calmodulin-dependent protein kinase II by k252a and its derivative, KT5926. Biochem Biophys Res Commun 181:423-429.

He Y, Yao Z, Gu Y, Kuang G, Chen Y (1992) Nerve growth factor promotes collateral sprouting of cholinergic fibers in the septohippocampal cholinergic system of aged rats with fimbria transection. Brain Res 586:27-35.

Heffner CD, Lumsden AGS, O'Leary DDM (1990) Target control of collateral extension and directional axons growth in the mammalian brain. Science 247:217-220.

Heumann R (1994) Neurotrophin signalling. Curr Opin Neurobiol 4:668-679.

Hoyle GW, Mercer EH, Palmiter RD, Brinster RL (1993) Expression of NGF in sympathic neurons leads to excessive axon outgrowth from ganglia but decreased terminal innervation within tissues. Neuron 10:1019-1034.

Inoue A, Sanes JR (1997) Lamina-specific connectivity in the brain: regulation by $\mathrm{N}$-cadherin, neurotrophins, and glycoconjugates. Science 276:1428-1431.
Jackson TR, Blader IJ, Hammonds-Odie LP, Burga CR, Cooke F, Hawkins PT, Wolf AG, Heldman KA, Theibert AB (1996) Initiation and maintenance of NGF-stimulated neurite outgrowth requires activation of a phosphoinositide 3-kinase. J Cell Sci 109:289-300.

Jian H, St. Ulme D, Dickens G, Chabuk A, Lavarreda M, Lazarovici P, Guroff G (1997) Both p $140^{\text {trk }}$ and p $75^{\text {NGFR }}$ nerve growth factor receptors mediate nerve growth factor calcium uptake. J Biol Chem 272:6835-6837.

Kadhim H, Bhide P, Frost DO (1993) Transient axonal branching in the developing corpus callosum. Cereb Cortex 3:551-556.

Kaethner RJ, Stuermer CAO (1992) Dynamics of terminal arbor formation and target approach of retinotectal axons in living zebrafish embryos: a time-lapse study of single axons. J Neurosci 12:3257-3271.

Kaplan DR, Stephens RM (1994) Neurotrophin signal transduction by the trk receptor. J Neurobiol 25:1404-1417.

Kaplan DR, Martin-Zanca D, Parada LF (1991) Tyrosine phosphorylation and tyrosine kinase activity of the trk proto-oncogene product induced by NGF. Nature 350:158-160.

Kennedy TE, Tessier-Lavigne M (1995) Guidance and induction of branch formation in developing axons by target-derived diffusible factors. Curr Opin Neurobiol 5:83-90.

Kimura K, Hattori S, Kabuyama Y, Shizawa Y, Takayanagi J, Nakamura S, Toki S, Matsuda Y, Onodera K, Fukui Y (1994) Neurite outgrowth of PC12 cells is suppressed by wortmannin, a specific inhibitor of phosphatidylinositol 3-kinase. J Biol Chem 269:18961-18967.

Koizumi S, Contreras ML, Matsuda Y, Hama T, Lazarovici P, Guroff G (1988) k252a: a specific inhibitor of the action of nerve growth factor on PC12 cells. J Neurosci 8:715-721.

Kotani K, Tonezawa K, Hara K, Ueda H, Kitamura Y, Sakaue H, Ando A, Chavanieu A, Calas B, Grigorescu F, Nishiyama M, Waterfield M, Kasuga M (1994) Involvement of phosphoinositide 3-kinase in insulinor IGF-1-induced membrane ruffling. EMBO J 13:2313-2321.

Kotani K, Hara K, Kotani K, Yonezawa K, Kasuga M (1995) Phosphoinositide 3-kinase as an upstream regulator of the small GTP-binding protein rac in the insulin signaling of membrane ruffling. Biochem Biophys Res Commun 208:985-990.

Kuang RZ, Kalil K (1994) Development of specificity in corticospinal connections by axonal collaterals branching selectively into appropriate spinal targets. J Comp Neurol 344:270-282.

Kudo N, Yamada T (1987) Morphological and physiological studies of development of the monosynaptic reflex pathway in the rat lumbar spinal cord. J Physiol (Lond) 389:441-459.

Kuhn TB, Schmidt MF, Kater SB (1995) Laminin and fibronectin guide posts signal sustained by opposite effects to passing growth cones. Neuron 14:275-285.

Lankford KL, Letourneau PC (1991) Roles of actin filaments and three second-messenger systems in the short-term regulation of chick dorsal root ganglion neurite outgrowth. Cell Motil Cytoskeleton 20:7-29.

Lankford KL, Letourneau PC (1989) Evidence that calcium may control neurite outgrowth by regulating the stability of actin filaments. J Cell Biol 109:1229-1243.

Lavie Y, Dybowski J, Agranoff BW (1997) Wortmannin blocks goldfish retinal phosphatidylinositol 3-kinase and neurite outgrowth. Neurochem Res 22:373-378.

Letourneau PC (1983) Difference in the organization of actin in the growth cones compared with the neurites of cultured neurons from chick embryos. J Cell Biol 97:963-973.

Lin C, Thompson CA, Forscher P (1994) Cytoskeletal reorganization underlying growth cone motility. Curr Opin Neurobiol 4:640-647.

Luo L, Jan LY, Jan Y (1997) Rho family small GTP-binding proteins in growth cone signalling. Curr Opin Neurobiol 7:81-86.

Mendelson B, Koerber HR, Frank E (1992) Development of cutaneous and proprioceptive afferent projection in the chick spinal cord. Neurosci Lett 138:72-76.

Muroya K, Hashimoto Y, Hattori S, Nakamura S (1992) Specific inhibition of NGF receptor tyrosine kinase activity by k-252a. Biochim Biophys Acta 1135:353-356.

Nakanishi S, Yamada K, Iwahashi K, Kuroda K, Kase H (1990) KT5926, a potent and selective inhibitor of myosin light chain kinase. Mol Pharmacol 37:482-488.

Ninomiya N, Hazeki K, Fukui Y, Seya T, Okada T, Hazeki O, Ui M (1994) Involvement of phosphatidylinositol 3-kinase in Fc $\gamma$ receptor signaling. J Biol Chem 269:22732-22737.

Nye SH, Squinto SP, Glass DJ, Stitt TN, Hantzopoulos P, Macchi MJ, Lindsay NS, Ip NY, Yancopoulos GD (1992) k-252a and staurospor- 
ine selectively block autophosphorylation of neurotrophin receptor and neurotrophin-mediated responses. Mol Biol Cell 3:677-686.

Oakley RA, Lefcort FB, Clary DO, Reichardt LF, Prevette D, Oppenheim RW, Frank E (1997) Neurotrophin-3 promotes the differentiation of muscle spindle afferents in the absence of peripheral targets. J Neurosci 17:4262-4274.

O'Leary DDM, Koester SE (1993) Development of projection neuron types, axon pathways, and patterned connections of the mammalian cortex. Neuron 10:991-1006.

O'Leary DDM, Stanfield BB (1985) Occipital cortical neurons with transient pyramidal tract axons extend and maintain collaterals to subcortical but not intracortical targets. Brain Res 336:326-333.

O'Leary DDM, Terashima T (1988) Cortical axons branch to multiple targets by interstitial axon budding: implications of target recognition and "waiting periods." Neuron 1:901-910.

O'Leary DDM, Heffner CD, Kutka L, Lopez-Mascaraque L, Missias A, Reinoso BS (1991) A target-derived chemoattractant controls the development of the corticopontine projection by a novel mechanism of axon targeting. Development [Suppl] 2:123-130.

Owen DJ, Logan A, Robinson PP (1989) A role for nerve growth factor in collateral reinnervation from sensory nerves in the guinea pig. Brain Res 476:248-255.

Ozaki S, Snider WD (1997) Initial trajectories of sensory axons toward laminar targets in the developing mouse spinal cord. J Comp Neurol 380:215-229.

Reif K, Nobes CD, Thomas G, Hall A, Cantrell DA (1996) Phosphatidylinositol 3-kinase signals activate a subset of Rac/Rho-dependent effector pathways. Curr Biol 6:1445-1455.

Ridley AJ (1994) Membrane ruffling and signal transduction. BioEssays 16:321-327.

Rodriguez-Viciana P, Warne P, Dhand R, Vanhaesebroeck B, Gout I, Fry MJ, Waterfield MD, Downward J (1994) Phosphatidylinositol-3-OH kinase as a direct target of ras. Nature 370:527-532.

Sato M, Lopez-Mascaraque L, Heffner CD, O'Leary DDM (1994) Action of a diffusible target-derived chemoattractant on cortical axon branch induction and directed growth. Neuron 13:791-803.

Sawai H, Clarke DB, Kittlerova P, Bray GM, Aguayo AJ (1996) Brainderived neurotrophic factor and neurotrophin-4/5 stimulate growth of axonal branches from regenerating retinal ganglion cells. J Neurosci 16:3887-3894.

Schnell L, Schneider R, Kolbeck R, Barde Y, Schwab ME (1994) Neurotrophin-3 enhances sprouting of corticospinal tract during development and after adult spinal cord lesion. Nature 367:170-173.

Schwegler G, Schwab ME, Kapfhammer JP (1995) Increase collateral sprouting of primary afferents in the myelin-free spinal cord. J Neurosci $15: 2756-2767$.

Tanaka E, Sabry J (1995) Making the connection: cytoskeletal rearrangements during growth cone guidance. Cell 83:171-176.

Tapley P, Lamballe F, Barbacid M (1992) k252a is a selective inhibitor of the tyrosine protein kinase activity of the trk family of oncogenes and neurotrophins receptors. Oncogene 7:371-381.
Tapon N, Hall A (1997) Rho, Rac and Cdc42 GTPases regulate the organization of the actin cytoskeleton. Curr Opin Cell Biol 9:86-92.

Theriot JA, Mitchison TJ (1991) Actin microfilament dynamics in locomoting cells. Nature 352:126-131.

Thomas JE, Venugopalam M, Galvin R, Wang Y, Bokoch GM, Vlahos CJ (1997) Inhibition of MG-63 cell proliferation and PDGFstimulated cellular processes by inhibitors of phosphatidylinositol 3-kinase. J Cell Biochem 64:182-195.

Ui M, Okada T, Hazeki K, Hazeki O (1995) Wortmannin as a unique probe for an intracellular signalling protein, phosphoinositide 3-kinase. Trends Biochem Sci 20:303-307.

Van der Zee CE, Fawcett J, Diamond J (1992) Antibody to NGF inhibits collateral sprouting of septohippocampal fibers following entorhinal cortex lesions in adult rats. J Comp Neurol 326:91-100.

Vlahos CJ, Matter WF, Hui KY, Brown R (1994) A specific inhibitor of phosphatidylinositol 3-kinase, 2-(4-morpolinyl)-8-phenyl-4h-1benzopyran-4-one (LY294002). J Biol Chem 269:5241-5248.

Wennstrom S, Hawkins P, Cooke F, Hara K, Yonezawa K, Kasuga M, Jackson T, Claesson-Welsh L, Stephens L (1994) Activation of phosphoinositide 3-kinase is required for PDGF-stimulated membrane ruffling. Curr Biol 4:385-393.

Weskamp G, Reichardt LF (1991) Evidence that biological activity of NGF is mediated through a novel subclass of high affinity receptors. Neuron 6:649-663.

Williams CD, Davenport RW, Dou P, Kater SB (1995) Developmental regulation of plasticity along neurite shafts. J Neurobiol 27:127-140.

Witte S, Stier H, Cline H (1996) In vivo observations of timecourse and distribution of morphological dynamics in Xenopus retinotectal axon arbors. J Neurobiol 31:219-234.

Wu D, Goldberg DJ (1993) Regulated tyrosine phosphorylation at the tips of growth cone filopodia. J Cell Biol 123:653-664.

Wu D, Wang L, Mason CA, Goldberg DJ (1996) Association of $\beta 1$ integrin with phosphotyrosine in growth cone filopodia. J Neurosci 16:1470-1478.

Yu W, Ahmad FJ, Baas PW (1994) Microtubule fragmentation and partitioning in the axon during collateral branch formation. J Neurosci 14:5872-5884.

Zhang J, King WD, Dillon S, Hall A, Feig L, Rittenhouse SE (1993) Activation of platelet phosphatidylinositide 3-kinase requires the small GTP-binding protein Rho. J Biol Chem 268:22251-22254.

Zhang L, Schmidt RE, Yan Q, Snider WD (1994) NGF and NT-3 have differing effects on the growth of dorsal root axons in developing mammalian spinal cord. J Neurosci 14:5187-5201.

Zheng Y, Glaven JA, Wu WJ, Cerione RA (1996) Phosphatidylinositol 4,5-bisphosphate provides an alternative to guanine exchange factors by stimulating the dissociation of GDP from Cdc42Hs. J Biol Chem 271:23815-23819.

Ziv NE, Spira ME (1997) Localized and transient elevations of intracellular $\mathrm{Ca}^{2+}$ induce the dedifferentiation of axonal segments into growth cones. J Neurosci 17:3568-3579. 